\title{
Engineering Students' Readiness to Transition to Emergency Online Learning in Response to COVID-19: Case of Qatar
}

\author{
Khalid Kamal Naji ${ }^{1}$, Xiangyun Du ${ }^{1 *}$, Faris Tarlochan ${ }^{1}$, Usama Ebead ${ }^{1}$, Mahmood A. Hasan ${ }^{1}$, \\ Abdulla Khalid Al-Ali ${ }^{1}$ \\ ${ }^{1}$ Qatar University, QATAR
}

Received 16 June 2020 - Accepted 27 July 2020

\begin{abstract}
This study examined engineering students' initial readiness to transition to emergency online learning in response to COVID-19 in Qatar. A theoretical framework is proposed for understanding the factors influencing students' readiness for change. Sequential explanatory mixed-method research was conducted, with 140 participants completing an online survey, of which 68 also contributed written reflections and 8 participated in semi-structured interviews. Exploratory factor analysis displayed a four-factor structure, including initial preparedness and motivation for online learning, self-efficacy beliefs about online learning, self-directed learning online, and support. The qualitative outcomes supported the four factors and provided further insight into their varied and nuanced manifestation. In accounting for the perceived impact of the factors on readiness, significant differences were identified regarding pedagogical mode, with students enrolled in PBL courses reporting higher readiness than those from non-PBL courses. The practical implications for preparing students for future emergency online learning are discussed.
\end{abstract}

Keywords: engineering students, readiness for change, emergency online learning, COVID-19, Qatar

\section{INTRODUCTION}

The current global COVID-19 pandemic has caused crises in all social spheres - health, the economy, and education. Most educational institutions worldwide have shifted teaching and learning activities to online modes. While the current literature outlines the various benefits of online education, such as flexibility and improved space for active learning and student engagement, several challenges are also identified, including increased faculty workload, student resistance, lack of opportunities for immediate questions, technical issues, lack of materials, decreased interest, and neglected material (Kebritchi, Lipschuetz, \& Santiague, 2017). Particularly, in the transition process from face-to-face to online learning, both instructors and students may experience feelings of disconnection and unclear expectations (Anderson, Imdieke, \& Standerford, 2011). However, these benefits and challenges were identified in well-planned programs in which students participated by choice, and online learning may not be the only learning mode. Hence, little knowledge is available regarding students' readiness to transition to emergency full-scale online learning, as happened in the Spring 2020 academic semester. Thus, there is a pressing need to understand students' initial readiness and experiences in such situations, which may challenge students' learning engagement and outcome.

This study explored the degree to which students are ready for the urgent shift to online learning and how they perceive their initial experiences in full-scale online learning in their engineering study programs. The study took place in the College of Engineering, Qatar University, Qatar, which, following the university policy, shifted all face-to-face courses to the online mode beginning March 15th, 2020. Before the change, all instructors were provided a three-day emergency training to implement online teaching using Blackboard Collaborate Ultra, WebEX, Microsoft Team, and Zoom. The university also provided students with several online training sessions, and, more importantly, each

(c) $\mathbf{2 0 2 0}$ by the authors; licensee Modestum. This article is an open access article distributed under the terms and conditions of the Creative Commons Attribution License (http://creativecommons.org/licenses/by/4.0/).

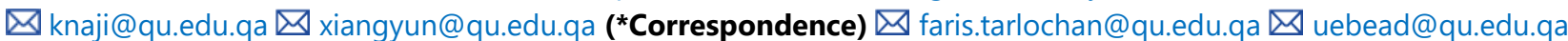

$\triangle$ mhassan@qu.edu.qa $\square$ abdulla.alali@qu.edu.qa 


\section{Contribution to the literature}

- Examining engineering students' initial readiness to transition to emergency online learning in response to COVID-19.

- Contributing to the field of engineering education through a theoretically sound framework that guided the empirical data collection and analysis, which in turn confirmed the suitability of the proposed framework.

- Providing engineering educators and leaders with information on how to effectively intervene in a change process, facilitate a smooth transition, and make action plans that prepare future engineers.

instructor was expected to train their students and prepare them for online learning. The study contributes to a conceptual understanding of students' initial experiences during an urgent shift to full-scale online education and provides evidence of factors supporting preparation for emergency online learning in engineering education and other disciplines.

\section{LITERATURE REVIEW}

\section{Online Education in Higher Education}

Online learning has become increasingly important as a new approach to education worldwide. Most higher education institutions are introducing online programs due to increased access to educational technology and the internet, the flexibility of such programs, and the opportunities they bring to learners, instructors, and institutions (Miller, 2014). Several research works have investigated online learning, including technology design and evaluation, pedagogical design (Hsu et al., 2012), students' and teachers' perceptions, preferences, and expectations, and styles of teaching and learning online (Martin, Ahlgrim-Delzell, \& Budhrani, 2017). Studies also collectively report that a major challenge lies in effectively transitioning from face-to-face teaching to online classrooms, with instructors and students reporting a disconnection from familiar teaching and learning methods, unclear expectations from institutions, and a lack of useful feedback from students to help instructors improve teaching (Anderson, Imdieke, \& Standerford, 2011; Artino \& Stephen, 2009). Also, instructors have encountered issues in acclimating to their new roles of supporting student learning online when they are not well prepared with the technology and instructional strategies, which in turn impacts student readiness and engagement with online learning, such as online participation and interaction (Kebritchi, Lipschuetz, \& Santiague, 2017).

In engineering education, studies on online learning have focused on the design and evaluation of learning systems and platforms and the perception and feedback of students and teachers (Hsu et al., 2012). Recent attention has been paid to the emerging development of immersive technologies for visualization and interactions, and their educational applications (Radianti, Majchrzak, Fromm, \& Wohlgenannt, 2020). These immersive environments have several reported advantages, including integrating e-learning, virtual reality and virtual worlds to improve learners' concentration and their ability to control over the learning environment (Wang, $\mathrm{Wu}$, Wang, Chi, and Wang, 2018), developing learners' psychomotor, cognitive, and affective skills (Jensen \& Konradsen, 2018), and engineering profession-related skills such as problem-solving, application of what has been learned, communication, and collaboration (Radianti, Majchrzak, Fromm, \& Wohlgenannt, 2020).

Despite the recognized advantages, challenges have been reported in online learning in engineering education. Students may experience a lower level of satisfaction, lack of interaction with instructors and peers, and reduced motivation to do the required coursework (Alkhatib, 2018). This may be due to engineering programs' unique demands for active and interactive laboratory sessions providing hands-on experiences and effective skills development (Potkonjak et al., 2016). For example, courses, such as engineering design, are rarely encountered with a full-scale online mode due to the need for technical skills and problemsolving abilities (Alkhatib, 2018). Therefore, an emergency shift to full-scale synchronous online learning can be difficult for engineering programs, and there is an urgent need to explore their preparation for this change and their initial experiences.

\section{Readiness for Change}

Despite the substantial documentation of online learning in higher education in general and engineering education in particular, there is little knowledge about online learning in the context of emergency shifts. Therefore, the literature on readiness for change is relevant in understanding students' feelings and reactions in this unique setting. The concept of readiness for change is not new. Readiness can be understood as "the cognitive precursor to the behaviors of either resistance to, or support for, a change effort" (Armeakis, Harris, \& Mossholder, 1993, p. 681). Originating in organizational studies, change readiness is defined as employees' beliefs regarding the appropriateness of, support for, and value of a change (Armenakis, Harris, \& Field, 1999, p. 291). Analyzing and assessing whether change recipients are ready for the targeted change is crucial to ensure a successful and effective implementation and sustainable change outcomes 
(Armenakis, Harris, \& Field, 1999; Holt, Armenakis, Feild, \& Harris, 2007). Alternatively, when unprepared for change, recipients (i.e., students) may display negative attitudes and low motivation, limiting their engagement, commitment, and long-term achievement (Du \& Chaaban, 2020).

In their systematic review, Holt, Armenakis, Feild, and Harris (2007) synergized four important aspects of readiness for change. The first aspect is the changespecific content, the thing or things being changed, which can be policies, rules, or conditions. A key factor of this aspect is whether and in which ways the change recipients think the targeted change is appropriate (e.g., the conditions of the learning environment changing from face-to-face to online). Second is the change process, which can be understood as how the change is implemented and the effectiveness of strategies used to support it, whereby leadership support plays a key role in successfully implementing change. Third is the internal context, referring to where the change is taking place because the circumstances of the substantive context may influence the change recipients' beliefs, attitudes, motivation, and intentions. In this aspect, a key factor is the discrepancy of change, which involves explaining to the change recipients the need for change and change contents. In addition, peer support and positive relationships are helpful and meaningful for individuals' readiness for change. Fourth are individual attributes, referring to the change recipients themselves, whose internal conditions play an influential role in their disposition, beliefs, attitudes, motivation, intentions, and behaviors. Key individual factors that might influence readiness are efficacy and valence, which refers to how the change recipients are confident in their capability and the support they receive is key to ensuring successful implementation (Holt and Vardaman, 2013). Equally important is the recipients' belief that the change will result in personal gains and benefits. Readiness influences intentions and reactions, exemplified by the attitudinal outcomes or actual behaviors that individuals may commit themselves to, which, in turn, impact change outcomes (Hersocovitch \& Meyer, 2002).

\section{Student Readiness for Emergency Change to Online Learning}

Context plays a critical role in the discussion of readiness (Bouckenooghe et al. 2009; Herscovitch \& Meyer, 2002; Holt, Armenakis, Feild, \& Harris, 2007; Holt \& Vardaman, 2013). The readiness for change literature has focused on change that was planned and initiated by organizational leadership. However, this was not the case in the current study, where the decision to change to emergency online teaching was reactive rather than proactive. Therefore, we conceptualize students' initial readiness for emergency change, linking to the literature of online learning. Accordingly, in this study we followed Holt and Vardaman's work (2013) to develop an operational definition of initial readiness as the degree to which students are individually and collectively primed, motivated, confident in and capable of enforcing change (in the context of amendments to emergency full-scale online learning). In addition, four aspects of sources are identified that may influence students' initial readiness for and experiences of an emergency transition to full-scale online learning, namely initial preparedness, motivation and interest, self-efficacy, self-directed learning, and external supports.

\section{Initial preparedness and motivation for online learning}

To facilitate effective online learning, it is essential to support students with initial preparedness for emergency change. In this study, we used the term preparedness to emphasize the organization's role in making the change recipient ready (Armeakis, Harris \& Mossholder, 1993; Hung, Chou, Chen, \& Own, 2010). Preparedness in this study means how the organization (university and programs in this context) informs, explains, and communicates the requested change (emergent shift to full-scale online learning) to the change recipients (students). Students should be informed of the change and be aware that the learning environment conditions are shifting from face-to-face to online. It is also important that students understand how the change is implemented and what strategies are being used to support online learning so that they can develop a strong belief in the appropriateness of the change. Accepting change can improve the chances of successfully implementing the change and maximizing change effectiveness (Bouckenooghe et al., 2009). In addition, they should accept the change as an appropriate way to achieve the educational objectives in the given context and be agentic and proactive in the change to develop professional competencies (Du, Chaaban, Sabah, Al-Thani, \& Wang, 2020). If students are given sufficient explanation that the change is needed, they are more likely to develop motivation and positive attitudes and establish trust and peer support in their environment (Hsu et al., 2012; Martin, Ahlgrimelzell \& Budhrani, 2017; Mayer, 2014). Motivation plays an important role in learning attitude, engagement, and agency, which significantly affect learners' performance (Artino \& Stephen, 2009; Ryan \& Deci, 2000).

\section{Self-efficacy beliefs about online learning}

Developed from social cognitive theory, self-efficacy refers to people's beliefs in their abilities to accomplish a task (Bandura, 1997). Not only is it an essential factor impacting readiness to manage change (Armeakis, Harris, \& Mossholder, 1993), but students' self-efficacy is also crucial in terms of how they develop beliefs about their abilities to manage their online learning to reach the targeted objectives. Students reporting higher selfefficacy with computers and the internet have been 
found to perform better in online learning tasks and performance (Hung, Chou, Chen, \& Own, 2010). Thus, students should be prepared with the necessary knowledge and skills regarding online learning tools and platforms when shifting from face-to-face to the online environment. Understanding students' efficacy of online participation and communication characteristics will also help instructors to adjust teaching strategies to enhance students' online learning experiences (Hung, Chou, Chen, \& Own, 2010).

\section{Self-directed learning online}

To support students' appreciation of online learning experiences, instead of focusing on lectures, students should be provided opportunities for active learning (Artino \& Stephen, 2009). Self-directed learning, referring to a process in which individuals take the initiative in understanding their learning needs, establishing learning goals, identifying learning resources, choosing and implementing appropriate learning strategies, and evaluating learning outcomes (Knowles, 1975), is an important concept in online learning. Moore and Kearsley (2005) report that learners with a high level of self-directed learning can make plans, identify resources, choose methods, and evaluate their performance to achieve self-established goals. Selfdirected online learners are more capable of taking responsibility and managing time and their actions, and they are more committed to online learning activities (Chu \& Tsai, 2009; Hung, Chou, Chen, \& Own, 2010; Yang \& Tsai, 2008; Stewart, 2007). Further, Chou (2012) found that highly self-directed students demonstrated active online learning patterns and were motivated to cope with different tasks and even heavy workloads. It is also suggested that self-directed learning is a key indicator predicting online academic performance (Chou, 2012; Chu \& Tsai, 2009; Hung, Chou, Chen, \& Own, 2010; Yang \& Tsai, 2008).

\section{Support}

Implementing change is highly contextual, and accordingly, support from the environment is needed (Du \& Chaaban, 2020; Du, Chaaban, Sabah, Al-Thani, \& Wang, 2020). Leadership support is key to improving motivation and self-efficacy to ensure the success of change efforts (Holt \& Vardaman, 2013). Previous studies (Chou, 2012; Chu \& Tsai, 2009; Hung, Chou, Chen, \& Own, 2010; Yang \& Tsai, 2008) have highlighted the importance of establishing online learning environments that support active learning and studentcenteredness to better support students in online learning. In particular, Miller (2014) suggested principles for an effective online learning environment: supporting peer-to-peer interaction, encouraging active student engagement in learning, emphasizing opportunities for students to practice, addressing individual needs and variety, and stressing higher thought processes. Also, students may need emotional care to ensure emotional readiness (Bouckenooghe et al., 2009; Herscovitch \& Meyer, 2002) and be willing to commit to online learning (Bouckenooghe et al., 2009).

These four critical aspects can be assumed to impact students' development of readiness for change, which, in turn, influences their reactions to the situation through affective commitment based on a belief in the inherent benefits of change, and they do not merely accept the change as an obligation or fear the risks involved (Herscovitch \& Meyer, 2002). The synthesis of the literature above is embedded in a context in which students chose to participate in an online educational activity, yet in the current urgent shift to online learning due to COVID-19, the change comes as external enforcement; hence, it is necessary to explore what factors impact students' readiness. The study is guided by the following questions:

1) What factors and sources are influencing engineering students' readiness for an emergency shift to full-scale online learning?

2) How do engineering students perceive the challenges and opportunities of their initial experiences of full-scale online learning?

\section{RESEARCH CONTEXT AND DESIGN}

Several terms have been interchangeably used in the literature of technology-supported education, including e-learning, distance education, and web-based learning. The research context in the current study is specific to synchronous online learning, referred to as a "permanent separation (of place) of the learner and instructor during planned learning events where instruction occurs in real-time such that students were able to communicate with other students and the instructor through text-, audio-, and/or video-based communication of two-way media that facilitated dialogue and interaction" (Martin, Ahlgrim-Delzell, \& Budhrani, 2017, p. 5).

The study takes place at Qatar University, where synchronous online learning is being urgently implemented in reaction to the COVID-19 lockdown. The major online platforms used are Blackboard Collaboration Ultra, WebEx, Microsoft Team, and Zoom. Instructors can additionally record synchronous lectures and provide them as online learning materials. In the College of Engineering, problem and project-based learning (PBL) was recently introduced in the teaching practice of some courses. While a few studies presented positive results of engineering students' learning experiences in a PBL environment $(\mathrm{Du}$, Ebead, Sabah, Ma, \& Naji, 2019; Du, Naji, Sabah, \& Ebead, 2020; Naji, Ebead, Al-Ali, \& Du, 2020), further educational and research attention to the effect of PBL implementation is needed (Chen, Kolmos, \& Du, 2020). In this study, we hypothesized that students who have been learning in a 
Table 1. Participant information

\begin{tabular}{lccc}
\hline Student numbers & PBL courses & Non PBL courses & Total \\
\hline Male & 67 & 31 & 98 \\
Female & 2 & 40 & 42 \\
Total & 69 & 71 & 140 \\
\hline
\end{tabular}

PBL environment may report different online learning experiences than students whose courses mainly focus on lectures. This is primarily because the nature of PBL demands interaction and teamwork. Hence, this study includes student participants from both PBL and nonPBL courses.

Explanatory sequential mixed-method research was employed for data generation in order to gain an overview of students' perceptions on their initial experiences (Creswell \& Clark, 2017), and further explore participants' thoughts, beliefs, feelings, experiences, and explanations for the survey results (Kvale \& Brinkmann, 2009). Data collection was conducted in two phases: Phase 1 was an online questionnaire survey, and Phase 2 was written reflections and interviews.

\section{PHASE 1: QUANTITATIVE STUDY}

\section{Participants}

The questionnaire survey was sent to 168 students from seven courses, four of which used the PBL method (PBL courses) (83 students, male $=80$, female $=3$ ), while the other three courses mainly used the lecture-based method (non-PBL courses) (85 students, male $=40$, female=45).

Table 1 provides an overview of participant information. A total of 140 students responded to the online questionnaire ( $83 \%$ respondence rate), of which $42(30 \%)$ were female, and 98 were male $(70 \%)$, and 69 were from PBL courses (49.3\%), and 71 (50.7\%) were from non-PBL courses. Due to the gender segregation in the undergraduate program enrollment (gender-mixed course are only allowed in the post-graduate programs), the male students were from four courses in the civil engineering program (three PBL and one non-PBL, male, years two and three and master's program), one course from the mechanical engineering program (PBL, male, year two), one course from the computer science program (years one and two), and female participants were only from the architecture design program (nonPBL, years two and three). The engineering programs are four-year-long in general, and students can choose courses across years. Therefore, some courses may have students of both years 2 and 3 .

\section{Questionnaire Survey}

A questionnaire survey was developed, drawing from extant research on readiness for change (Bouckenooghe et al., 2009; Du \& Chaaban, 2020; Herscovitch \& Meyer, 2002; Holt, Armenakis, Feild, \&
Harris, 2007; Holt \& Vardaman, 2013), learning motivation (Hsu et al., 2012; Martin, Ahlgrim-elzell \& Budhrani, 2017; Mayer, 2014; Ryan \& Deci, 2000), selfefficacy beliefs related to change (Armeakis, Harris, \& Mossholder, 1993; Bandura, 1997), and self-directed learning (Chou, 2012; Moore \& Kearsley, 2005). All these factors have been suggested as relevant to student readiness for online learning (Hung, Chou, Chen, \& Own, 2010). Following Creswell and Clark (2017), questionnaire development procedures included the following:

1) Internal review among the research team over several rounds, including four members familiar with the engineering programs, one expert in engineering education research, and one expert in quantitative studies and statistical analysis in education. At this stage, the survey included six constructs with 33 items on a five-point Likert-type scale: 1) initial preparedness and motivation for online learning, 2) self-efficacy beliefs about online learning, 3) self-directed learning online, 4) support, 5) online assessment and lab, and 6) overall perception and experience. The first four factors were based on the proposed theoretical framework, and the last two factors were based on engineering instructors' teaching practices and concerns. In particular, factor 5 (2 items) were based on the instructors' concerns about students' perceptions of online lab facilities, and factor 6 included 3 items on the students' overall perception about their initial experiences of full-scale online learning. For all items, students were invited to evaluate their agreement on to what degree the five factors contribute to their readiness for full-scale learning.

2) Three international educational research experts (including two in the field of online education) and three instructors from the engineering program were invited to review the survey to provide expert and content validation. All items were considered relevant and appropriate concerning the constructs and the research. Based on their suggestions, we adjusted most items to start with "I" except for the construct of "support." Minor revisions were made accordingly regarding the phrasing of items $3,4,8,9,11,16,17,18,27$, and 33 .

3) Since the survey was to be conducted in English, which is the official educational language in the engineering program, native English-speaking professionals proofread the items.

4) A pilot study was conducted with a different sample of students $(\mathrm{N}=8)$ to test the questionnaire's appropriateness and deficiencies. Construct 5), online assessment and lab, was removed based on pilot study feedback; the two items were "The online tools used to substitute for physical labs have been effective" and "The online assessment methods used in the course are appropriate and support the achievement of course objectives." While the instructors suggested on the importance to ask these questions, six of the eight 


\begin{tabular}{|c|c|c|c|c|}
\hline & 1 & 2 & 3 & 4 \\
\hline I understand there is an urgent need to shift to online learning in the & 0.661 & -0.003 & -0.018 & \\
\hline I believe the university's decision to shift to online learning is appropriate in the current situation. & 0.579 & 0.267 & -0.095 & \\
\hline Shifting to online learning can support me in reaching the objectives of this academic semester. & 0.734 & 0.241 & 0.206 & \\
\hline I have received clear instruction on how to adapt to the online learning situation. & 0.615 & 0.236 & 0.299 & \\
\hline 5. I am able to devote myself to the new way of learning through online platforms. & 0.630 & 0.494 & 0.253 & \\
\hline 6. I am highly motivated to sustain my learning through online platforms. & 0.697 & 0.343 & 0.451 & \\
\hline 7. It is interesting for me to learn in this new way through online platforms. & 0.648 & 0.449 & 0.316 & \\
\hline 8. Despite the challenges, I will manage my online learning this semester. & 0.720 & 0.265 & 0.280 & \\
\hline 9. I will benefit from this experience of shifting to online learning in the long run. & 0.778 & 0.242 & 0.148 & \\
\hline 0 . I consider this shift to online learning as a positive experience. & 0.819 & 0.341 & 0.215 & \\
\hline $\begin{array}{l}\text { 11. I feel confident in performing the basic functions of online learning platforms, such as Black Board } \\
\text { Collaborate, Zoom, WebEx, or equivalent, used for online study. }\end{array}$ & 0.244 & 0.281 & 0.337 & \\
\hline 12. I feel cc & 0.411 & 0.176 & 0.198 & \\
\hline 13. If & 0.001 & 0.535 & 0.217 & \\
\hline $\begin{array}{l}\text { 14. I feel confident in using online tools (e.g. email, media tools, discussion platform) to effectively } \\
\text { communicate with others, such as posting questions, expressing myself (on emotional and academic ce }\end{array}$ & 0.287 & 0.401 & 0.277 & 0.6 \\
\hline 15. I set up learning goals in response to the urgent shift to online learning. & 0.441 & 0.041 & 0.590 & 0.4 \\
\hline 16. I & 0.488 & 0.080 & 0.622 & \\
\hline 17. I & 0.483 & -0.008 & 0.535 & \\
\hline 18. I & 0.363 & 0.156 & 0.497 & \\
\hline 19. I & 0.456 & 0.141 & 0.756 & \\
\hline 20. I c & 0.465 & 0.103 & 0.713 & \\
\hline (e.g. instant messages, Internet surfing). & 0.651 & 0.245 & 0.415 & 0.0 \\
\hline 22. I se & -0.156 & 0.517 & 0.594 & 0.0 \\
\hline 23. I am & 0.580 & 0.365 & 0.412 & 0.17 \\
\hline 24. I regularl & 0.110 & 0.222 & 0.707 & 0.1 \\
\hline $\begin{array}{l}\text { 25. The choice of the platform (e.g. Blackboard Collaborate Ultra or WebEx) in the courses I attend is } \\
\text { appropriate. }\end{array}$ & 0.164 & 0.662 & 0.166 & \\
\hline 26. The online learning environment has provided convenient facilities for discussion during class hours (e.g. & 0.286 & 0.651 & 0.181 & 0.3 \\
\hline 27. The course instructor is sufficiently prepared for online teaching. & 0.305 & 0.791 & 0.023 & 0.1 \\
\hline 28. There is sufficient contact with the course instructor. & 0.303 & 0.815 & 0.083 & \\
\hline 29. I have been provided with sufficient materials to support my online learning & 0.253 & 0.771 & 0.161 & 0.1 \\
\hline
\end{tabular}

29. I have been provided with sufficient materials to support my online learning.

students in the pilot study commented that although these two items were highly relevant to the quality of online teaching, each course involved different levels and forms of lab work and assessment methods, which made any judgment contextually dependent. Thus, the overall survey results would not be fair. In addition, several items were reworded and clarified to enhance the meanings of the sentences. For example, such rewording distinguished the use of online platforms and online tools, provided concrete examples of online platforms (Blackboard Collaborate Ultra or WebEx), and clarified that the items of the self-directed learning factor were in online settings (e.g., "I manage my time well in an online learning environment"). Subsequently, five constructs with 31 items remained.

5) The final version of the survey was distributed five weeks after the transition to online learning through a Google Form link sent to students by email and through the courses' online platforms. Two reminders were sent during the following two weeks, and 145 surveys were returned, whereby 140 of these were complete and valid for data analysis.

\section{Quantitative Analysis and Results}

This section presents the quantitative analysis and the results of the study while answering research question one.

\section{Validity}

Exploratory factor analysis (EFA) was conducted to explore the factor structure of the survey in Qatar's engineering programs. Prior to EFA loading, the KaiserMeyer-Olkin (KMO) test was performed to verify the critical assumptions underlying the factor analysis, with a sampling adequacy result of .926 and a Bartlett test of sphericity result of $\mathrm{X} 2=3.870, \mathrm{df}=406, \mathrm{p}<0.000$. The EFA was conducted using the principal components' extraction with an eigenvalue greater than $1.00(\mathrm{~F} 1=$ 15.137. $\mathrm{F} 2=2.235, \mathrm{~F} 3=1.698$ and $\mathrm{F} 4=1.436$ ). Varimax rotation was conducted with an intention to maximize the variance correlation with each principal component and to simplify the loadings of items by removing the middle ground and more specifically identifying the factor upon which data load (Forina, Armanino, Lanteri, \& Leardi, 1989). Subsequently, items 5 and 6 were deleted because their correlation with the total score was less than 0.3 . This may be due to the two items' negative statements: "I am skeptical that shifting to online learning can maintain the quality of teaching and learning" and "I am skeptical that shifting to online learning can maintain my previous academic achievement." As a result, 29 items remained.

From Table 2, it was found that some items were multiple loaded in two factors (items 21 and 23). Various 


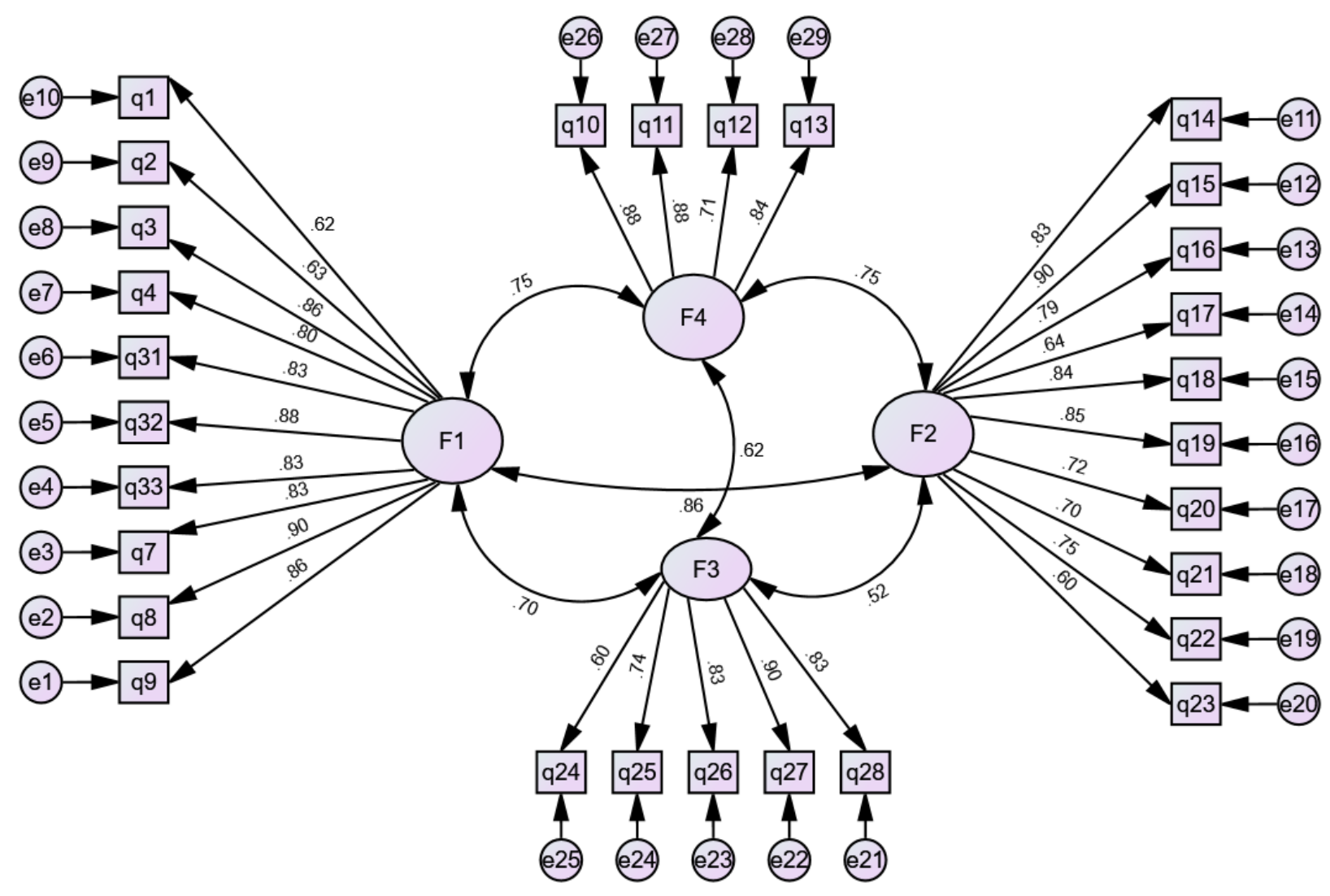

Figure 1. The results of Confirmative factor analysis using AMOS program

ways for justification have been suggested. For example, Al-Swidi, et al. (2014) recommended to consider the highest value of the loading in case of interference between factors. A different suggestion by Henseler, Ringle, and Sarstedt (2015) showed that when items were found to have multiple loading in EFA, justification shall be provided in relation to the particular content of the items and to the logic of theories. In such a case, the Confirmative Factor Analysis may be used to assess the cross-loading. In this study, items 21 and 23, although were highest loaded in factor one, were considered in factor three to follow the logic of the literature on selfdirected learning as discussed earlier in this paper. This choice was also to follow the content validity by experts and the instructors' suggestions. Following Henseler, Ringle, and Sarstedt (2015), a Confirmative Factor Analysis was conducted using AMOS 25 programs to further assess the cross-loading, and Figure 1 reports the CFA results.

CFA showed the Goodness of fit statistics results which better fit of the model with the study results suggested in Table $2\left(d f=371, \chi^{2}=1096.50, \mathrm{NFI}=0.940\right.$, RMSEA $=.09, \quad$ AGFFI $=0.107, \quad$ CFI $=0.850, \quad$ GFI $=0.920$. According to the results reported in Figure 1, the factor loadings for all subcategories were significant and exceeded the suggested cut-off level of 0.6 (Ahmed, 2019).
Combining the results of the EFA and CFA, four factors were identified, accounting for $71.4 \%$ of the total variance. The extracted factors were 1) initial preparedness and motivation for online learning (10 items), 2) self-efficacy beliefs about online learning (4 items), 3) self-directed learning online (10 items), and 4) support (5 items). The results are close to the initial survey design based on the theoretical framework, except that the final construct on individual overall perceptions (items 8,9 , and 10) was loaded on the same factor as construct 1 , the initial preparedness and motivation for online learning. These three items were merged into the final version of factor 1 because the meanings are logically close.

\section{Reliability}

Cronbach's coefficient alpha was computed to test the survey's reliability, and values above 0.70 were considered acceptable. These coefficients indicated high internal consistencies for each construct, as revealed in Table 3.

\section{Descriptive statistics}

The descriptive statistics for the final version of the survey were also computed. Table 4 reports the means and standard deviation of each factor. The factor that 
Table 3. Cronbach Reliability Coefficients $(\mathrm{N}=140)$

\begin{tabular}{llcc}
\hline Factors & Items & $\begin{array}{c}\text { No. of } \\
\text { Items }\end{array}$ & $\begin{array}{c}\text { Cronbach } \\
\text { Alpha }\end{array}$ \\
\hline 1 & $1,2,3,4,5,6,7,8,9,10$ & 8 & 0.949 \\
2 & $11,12,13,14$, & 9 & 0.895 \\
3 & $15,16,17,18,19,20,21,22,23,24$ & 6 & 0.920 \\
4 & $25,26,27,28,29$ & 5 & 0.886 \\
Total & & 29 & 0.967 \\
\hline
\end{tabular}

Table 4. Means and Standard Deviations of Factors ( $\mathrm{N}=140)$

\begin{tabular}{lcc}
\hline Factors & Mean & St dev \\
\hline Preparedness for online learning & 3.90 & 1.07 \\
Self-efficacy beliefs for online learning & 4.03 & 1.00 \\
Self-directed learning online & 3.54 & 0.96 \\
Support & 3.97 & 0.88 \\
Total & 3.86 & 0.86 \\
\hline
\end{tabular}

received the highest mean average was self-efficacy beliefs about online learning (Mean $=4.03, \mathrm{sdv}=1.00$ ), and the factor that received the lowest mean average was self-directed learning (Mean=3.54, sdv=0.96).

Paired sample t-tests were conducted to compare the means of the three factors. As displayed in Table 5, although no significant differences were found among them, the factors of preparedness, self-efficacy beliefs, and support were found to influence engineering students' online learning more significantly than did self-directed learning.

\section{Geographical factors}

An independent sample t-test was used to examine whether there were significant differences between the two demographic sets (gender and course (PBL vs. nonPBL)) for each of the four emerging factors. The results suggest no significant differences between male and female students in most aspects, except male students reported significantly higher self-efficacy beliefs about online learning (factor 2) than female students, as Table 6 shows.

The survey results indicate that students from PBL courses generally reported significantly higher readiness than those from non-PBL courses $(p<.05)$, as illustrated in Table 7. This is particularly true regarding factor 1 , preparedness for online learning, and factor 2, selfefficacy beliefs about online learning. No significant differences were found for factor 3, self-directed learning, and factor 4, support.

\section{PHASE 2: QUALITATIVE STUDY}

\section{Data Collection and Participants}

The quantitative study results in Phase 1 identified factors that impact students' readiness for online learning. A qualitative study was conducted in Phase 2 aiming first to triangulate the quantitative data results and second, to provide explanations and interpretations of the patterns identified in Phase 1 (Creswell \& Clark, 2017). Therefore, two types of qualitative data, written reflections, and interviews, were collected to offer insight and better understand the phenomenon under investigation (Cohen, Manion, \& Morrison, 2013).

Students' written reflections were also collected online by inviting students to write down their reflections on their personal experiences and individual opinions on teaching and learning during the emergency

Table 5. Paired Samples Test $(\mathrm{N}=140)$

\begin{tabular}{|c|c|c|c|c|c|c|c|c|}
\hline & Factor & Mean & $\mathrm{N}$ & Std. Deviation & Std. Error Mean & $\mathrm{t}$ & $\mathrm{df}$ & Sig. (2-tailed) \\
\hline \multirow[t]{2}{*}{ Pair 1} & factor1 & 3.90 & 140 & 1.071 & 0.091 & \multirow{2}{*}{-1.899} & \multirow{2}{*}{139} & \multirow{2}{*}{0.060} \\
\hline & factor2 & 4.03 & 140 & 1.003 & 0.085 & & & \\
\hline \multirow[t]{2}{*}{ Pair 2} & factor1 & 3.90 & 140 & 1.071 & 0.091 & \multirow{2}{*}{6.866} & \multirow{2}{*}{139} & \multirow{2}{*}{0.000} \\
\hline & factor3 & 3.54 & 140 & 0.965 & 0.082 & & & \\
\hline \multirow[t]{2}{*}{ Pair 3} & factor1 & 3.90 & 140 & 1.071 & 0.091 & \multirow{2}{*}{-1.116} & \multirow{2}{*}{139} & \multirow{2}{*}{0.266} \\
\hline & factor4 & 3.97 & 140 & 0.881 & 0.074 & & & \\
\hline \multirow[t]{2}{*}{ Pair 4} & factor2 & 4.03 & 140 & 1.003 & 0.085 & \multirow{2}{*}{7.312} & \multirow{2}{*}{139} & \multirow{2}{*}{0.000} \\
\hline & factor3 & 3.54 & 140 & 0.965 & 0.082 & & & \\
\hline \multirow[t]{2}{*}{ Pair 5} & factor2 & 4.03 & 140 & 1.003 & 0.085 & \multirow{2}{*}{0.804} & \multirow{2}{*}{139} & \multirow{2}{*}{0.423} \\
\hline & factor4 & 3.97 & 140 & 0.881 & 0.074 & & & \\
\hline \multirow[t]{2}{*}{ Pair 6} & factor3 & 3.54 & 140 & 0.965 & 0.082 & \multirow{2}{*}{-6.506} & \multirow{2}{*}{139} & \multirow{2}{*}{0.000} \\
\hline & factor4 & 3.97 & 140 & 0.881 & 0.074 & & & \\
\hline
\end{tabular}

Table 6. Gender Variation

\begin{tabular}{|c|c|c|c|c|c|c|c|c|}
\hline Gender & & $\mathrm{N}$ & Mean & Std. Deviation & Std. Error Mean & $\mathrm{t}$ & $\mathrm{df}$ & Sig. (2-tailed) \\
\hline \multirow[t]{2}{*}{ factor1 } & Female & 42 & 3.826 & 1.154 & 0.178 & \multirow{2}{*}{-0.507} & \multirow[b]{2}{*}{138} & \multirow[b]{2}{*}{0.613} \\
\hline & Male & 98 & 3.927 & 1.038 & 0.105 & & & \\
\hline \multirow[t]{2}{*}{ factor2 } & Female & 42 & 3.732 & 1.286 & 0.198 & \multirow{2}{*}{-2.312} & \multirow{2}{*}{138} & \multirow{2}{*}{0.022} \\
\hline & Male & 98 & 4.153 & 0.829 & 0.084 & & & \\
\hline \multirow[t]{2}{*}{ factor3 } & Female & 42 & 3.614 & 1.046 & 0.1614 & \multirow{2}{*}{0.578} & \multirow{2}{*}{138} & \multirow{2}{*}{0.564} \\
\hline & Male & 98 & 3.511 & 0.932 & 0.0942 & & & \\
\hline \multirow[t]{2}{*}{ factor4 } & Female & 42 & 3.880 & 1.068 & 0.165 & \multirow{2}{*}{-0.829} & \multirow{2}{*}{138} & \multirow{2}{*}{0.409} \\
\hline & Male & 98 & 4.012 & 0.791 & 0.080 & & & \\
\hline \multirow[t]{2}{*}{ Total } & Female & 42 & 3.762 & 1.047 & 0.1616 & \multirow{2}{*}{-0.869} & \multirow{2}{*}{138} & \multirow{2}{*}{0.386} \\
\hline & Male & 98 & 3.901 & 0.772 & 0.0780 & & & \\
\hline
\end{tabular}


Table 7. Variation by PBL vs. Non-PBL Courses

\begin{tabular}{|c|c|c|c|c|c|c|c|c|}
\hline PBL VS. NON-PBL & & $\mathrm{N}$ & Mean & Std. Deviation & Std. Error Mean & $\mathrm{t}$ & $\mathrm{df}$ & Sig. (2-tailed) \\
\hline \multirow[t]{2}{*}{ factor1 } & $\mathrm{N}$ & 71 & 3.631 & 1.254 & 0.149 & \multirow{2}{*}{-3.063} & \multirow{2}{*}{138} & \multirow{2}{*}{0.003} \\
\hline & $\mathrm{Y}$ & 69 & 4.170 & 0.759 & 0.091 & & & \\
\hline \multirow[t]{2}{*}{ factor2 } & $\mathrm{N}$ & 71 & 3.831 & 1.142 & 0.136 & \multirow{2}{*}{-2.383} & \multirow{2}{*}{138} & \multirow{2}{*}{0.019} \\
\hline & $\mathrm{Y}$ & 69 & 4.228 & 0.794 & 0.096 & & & \\
\hline \multirow[t]{2}{*}{ factor3 } & $\mathrm{N}$ & 71 & 3.461 & 1.1028 & 0.1309 & \multirow{2}{*}{-1.015} & \multirow{2}{*}{138} & \multirow{2}{*}{0.312} \\
\hline & Y & 69 & 3.626 & 0.798 & 0.096 & & & \\
\hline \multirow[t]{2}{*}{ factor4 } & $\mathrm{N}$ & 71 & 3.920 & 0.988 & 0.117 & \multirow{2}{*}{-0.696} & \multirow{2}{*}{138} & \multirow{2}{*}{0.487} \\
\hline & Y & 69 & 4.024 & 0.760 & 0.091 & & & \\
\hline \multirow[t]{2}{*}{ Total } & $\mathrm{N}$ & 71 & 3.711 & 0.988 & 0.117 & \multirow{2}{*}{-2.093} & \multirow{2}{*}{138} & \multirow{2}{*}{0.038} \\
\hline & Y & 69 & 4.012 & 0.684 & 0.082 & & & \\
\hline
\end{tabular}

shift to online education in QU during the COVID-19 pandemic (example questions see Appendix 1). A total of 82 students, all of whom were survey respondents, participated in the written reflection through online forms; among them, 68 were from PBL courses (all male), and 14 were from non-PBL courses (male $=6$, female $=8$ ). The written reflections had a length of 1-6 pages, adding up to 228 pages of text for analysis.

Finally, semi-structured interviews were conducted to understand participants' perceptions and experiences further and to explore supplementary explanations. Following interview techniques suggested by Kvale and Brinkmann (2009), participants were invited to share their perceptions of their experiences with online learning, while explanation and elaborations of certain results were obtained from the survey and written reflection data (example questions see Appendix 1). Eight students who had participated in both the survey and written reflection voluntarily participated in the interviews; of these, four were from PBL courses (all male), and four were from non-PBL courses (male $=2$, female $=2$ ). The interviews were conducted individually online via Zoom or mobile phone at the participants' convenience. Each interview lasted 20-40 minutes, was conducted in English, audio-recorded, and transcribed to text for analysis (51 pages of transcription). Due to the anonymity in data generation, we were not able to link between data sources.

\section{Data Analysis}

The gathered data amounted to 279 pages of qualitative data in text for analysis. Multiple procedures were conducted in the analysis of the qualitative data. First, to run through the written reflection and interview transcript text, we employed a theory-driven approach following the four factors identified as part of the theoretical framework and the results of quantitative analysis (initial preparedness and motivation for online learning, self-efficacy beliefs about online learning, selfdirected learning online, and support). This step further triangulated the survey results and further validated the four factors in the emergency online learning environment. Second, a thematic analysis was conducted to explore emerging themes, subthemes, and patterns. Through thematic analysis focusing on meaning condensation, outlines of the meanings expressed by the participants were coded and categorized into shorter formulations (Kvale \& Brinkmann, 2009). The initial findings were then used to triangulate the survey results and further explore participants' elaboration and the reasons for the patterns (Kvale \& Brinkmann, 2009).

Table 8 illustrates the coding scheme with sample emerging themes and data. The combined deductive and inductive process confirmed the initial themes suggested by the framework, based on which emerging themes were identified, as presented in Table 8. In this way, we confirmed that the proposed framework would be suitable for the study's aims and supports an overall understanding of the factors impacting students' readiness for emergency online learning.

Following Guba and Lincoln (2005), we have made efforts to improve the trustworthiness of the study by triangulating data from multiple sources and through a collaborative data analysis process. The analysis was conducted individually by the research team before the collaborative discussion was conducted, and a consensus was reached.

\section{Qualitative Findings}

The qualitative data analysis revealed patterns influencing engineering students' readiness for online learning. This section first triangulates the quantitative results in response to research question one, then provides an elaboration of each factor with identified subthemes and emerging themes, including illustrative comments from the participants.

\section{Factor 1: Initial preparedness and motivation}

Appropriateness: A high-level agreement was reached by all participants in both the written reflection and interviews that the transition to online learning was an appropriate decision, providing them with an opportunity to continue their studies this semester. None of the students preferred alternative solutions, such as postponing the semester. As one student wrote, "I appreciate this online study option so that we can reach the curriculum goals of this semester without wasting a few months." 
Table 8. Coding Scheme with Sample Themes and Data

Themes suggested by the proposed Emerging themes Samples

framework and survey results examples

Initial preparedness and Appropriateness "This shift to online learning is helpful for us to reach the expected objectives motivation and finish this semester."

Communication "I think the instructors are generally clear about what would happen in the online sessions."

Motivation, values, "I think changing to online a good idea for now and I expect to learn more and attitudes about how online works

Self-efficacy beliefs about online Technology efficacy "We have already been familiar with different online tools, it did not take a learning long time before I got used to the online learning platforms used in the course."

General online "It is indeed a new situation and there have been challenges, but I think I will learning efficacy manage this."

Self-directed learning online Goals and time "I made a plan in order to be able to reach the course objectives, but management (goals sometimes I could not follow the plan due to disturbance at home. I shall work and plans) more on my time management."

Seeking for help "When I could not follow the lecture, I sent questions through the online chat function or sent an email with the question after the class, the instructors usually answer quickly."

Reflection and "Looking back I think it would have worked better if we spent more time on evaluation team building before the lockdown, then we would be able to communication easier now."

\begin{tabular}{lll}
\hline Support - overcoming challenges & Personal & $\begin{array}{l}\text { "I have to put a note outside of my door to tell my brothers no to disturb me } \\
\text { when I study online." }\end{array}$ \\
$\begin{array}{ll}\text { Peer support and } \\
\text { teamwork }\end{array}$ & $\begin{array}{l}\text { "It was a good help to work in a team in such a situation, since we met online } \\
\text { Institutional } \\
\text { regularly to discuss...I feel in this way I am on the right track." }\end{array}$ & $\begin{array}{l}\text { "I wish in the future we will be bettered supported on how to use the software } \\
\text { when we are not on campus. Some software we use in this course was so } \\
\text { heavy to download and open, it was not easy to get technical support online } \\
\text { on this matter." }\end{array}$ \\
&
\end{tabular}

Communication: More than $80 \%$ of participants $(\mathrm{N}=56)$ gave positive feedback on the clear instruction and preparation for the shift by the program and college. They received emergency training workshops two days before the online learning was implemented, and each program and course instructor made efforts to provide clear guidelines on how each course would be restructured. This was further confirmed during interviews, as one student said,

"It was nice that we were provided with the instructions, which somehow reduced the insecurity. We know they (the program) are working on it, and the communication went through successfully, and the instructors were quite motivating."

Nevertheless, several students $(\mathrm{N}=15)$ wrote about "confusion" and "chaos" in the first two weeks of online learning due to a lack of clear orders and instructions. As one student reflected in the interview, "the instructors may have provided lots of information, but I was confused and could not find out how to do things efficiently."

Motivation, values, and attitudes: Most student participants expressed their motivation and interest in online learning. In contrast, the majority of students $(\mathrm{N}=62)$ expressed their appreciation of the online experience through the advantages and benefits they perceived, including "learning how to use new online platforms," "learning more about technology," "saving traveling time," "experiencing an alternative way of learning," and "opportunity to catch up." As one student wrote,

\section{It is a good way to maintain and save time for the semester. It is a very safe way to stay in touch with the curricular activities, and it is also a great use of quarantine. It is the best way to stay in touch with the world through education.}

Another common subtheme was students' experience of personal growth by adjusting themselves during the emergency shift, as around half the students reflected in their writing. One example was,

We have to keep working on ourselves, no matter what happens and no matter what the circumstances are, in order to keep learning and to benefit from every single resource that we encounter and to keep trying to build and educate ourselves for as long as we can. I have experienced a lot of freedom and flexibility during online learning and have seen a significant improvement in my productivity and willingness to learn in general.

Noncontradictory to their articulation of a positive attitude towards the shift, participants also expressed "nervousness" and "feeling insecure" at the beginning when they were unsure exactly what would happen. In particular, they worried whether this shift would negatively influence their grades. This concern was 
particularly addressed in all the written reflections of non-PBL students, who also mentioned "loneliness" while studying at home. While some students from PBL courses mentioned the same insecurity regarding grades, they did not mention loneliness, as their ongoing projects involved teamwork.

\section{Factor 2: Self-efficacy beliefs about online learning}

In both qualitative data sources, students reported positive self-efficacy beliefs about online learning regarding their confidence in the use of technology and in managing general online learning. They expressed their confidence in their ability to manage the online tools, gather information for course needs through internet sources, and communicate effectively for course purposes, including posting questions and expressing and discussing ideas with peers and instructors. As one student wrote,

I perceive it (Blackboard) as a good way or platform for online participation; it provides a good option for participation in our online learning process. Everyone can easily participate in an online class. Everyone can easily talk and give arguments and explain what he/she wants to explain. We can share documents, files, folders, or any type of audio or video content on this platform.

As explained in the interviews, this general high selfefficacy in relation to online learning may be linked to the fact that participants are engineering students who are familiar with the concept of working and learning using technology. This confidence also became a source of motivation for online learning.

Nevertheless, the written reflections of six female students from non-PBL courses mentioned their concern about their capability to manage all their studies online initially and stated that they felt more secure after some initial weeks of experience. As one female student explained in the interview, "it can be stressful to have the ambition to study and at the same time need to support the homeschooling of children." A similar lack of confidence was reported in the written reflections of five of the six male participants from non-PBL courses. As one male student explained in the interview, "sometimes I feel like I am so far away from things I was used to; this makes me feel more unsure whether I am doing well in my studies."

\section{Factor 3: Self-directed learning online}

Goals and time management: In the survey, participants reported generally positive results in setting up learning goals (Mean= 3.61, $\mathrm{sdv}=1.27$ ) and carrying out plans (Mean=3.71, sdv=1.18). Although this was further confirmed in their written reflection, their reported goal in online learning was to reach the curriculum objectives and earn the same grade as they had expected at the beginning of the semester, and the majority of them $(\mathrm{N}=59)$ reflected on time management as a challenge and a benefit of learning. In particular, more than $60 \%$ of the students $(\mathrm{N}=51)$ reported that studying online supported their time management, in particular regarding saving transportation time. However, around half the students encountered distraction due to their home situations or other online tools, such as phones or other programs on the computer. Nevertheless, half the students reported that the instructors' schedules helped them monitor their plan and regularly check their progress. As one wrote,

\section{The emergent shift to another way of learning taught us how to adapt quickly to any changes in any circumstances. This experience will help me in the long run as it taught me to be more self-disciplined. I realized the importance of doing things on time or even ahead of time. The motivation to study in an online course comes from me as I take responsibility for everything I do.}

Both sides of time management were further elaborated on in the interviewees, with all interviewed students stating that working at home made daily life more efficient since they did not have to travel. At the same time, students admitted that time management remained a big challenge even once they were familiar with the online learning system. As one explained, "I am the enemy of myself; I have to always find the way to motivate myself and tell myself to concentrate."

Another subtheme related to self-monitoring in online learning is seeking help. While most female participants' written reflections said that they would call for help when encountering IT issues or difficulties following the course content, some male students reported writing to the instructor to ask for help only after they had tried several times without success. During interviews, four male students explained that they believed they could figure it out on their own, while both female students said asking for help could help solve things efficiently, meaning they could move on quickly.

Reflection and evaluation: Although students reported positive results regarding self-reflection and evaluation $(\mathrm{M}=3.63, \mathrm{sdv}=1.02)$, and reflection on the benefits of learning online was also well-addressed in their written reflections, students provided little information on self-evaluation. When asked about selfevaluation during the interviews, students mainly related the topic to whether they could earn their expected grades. Stress was another subtheme that emerged in this topic. Most students $(\mathrm{N}=51)$ mentioned the stress they encountered during the online learning experience as they tried to determine the best strategy and dealt with uncertainty regarding academic outcomes (grades). As one student wrote, 
I set up timelines for my own plan, but sometimes I was not efficient for many reasons, and when I realized that I was not able to reach the deadlines, I became stressed, without knowing whether I am able to get the same grade as I used to do.

\section{Factor 4: Support - overcoming challenges}

Students reported encountering personal, relational, and environmental challenges during their initial experience of online learning.

Personal challenges: The most frequently mentioned personal challenge to studying online during lockdown was a home disturbance. These home conditions included a lack of space for individual isolation during online sessions, speed of home internet connections, and other tasks such as supporting children or siblings' homeschooling. As one student wrote, "I wish I could have more space and peace at home so I can concentrate without having my little brothers knocking at the door and shouting around all the time." Another student mentioned in the interview that his home internet could be a barrier when everyone (four homeschooling siblings and parents working from home) used the online video at the same time. In these cases, the student sometimes chose to revisit recorded lectures or other online materials to catch up. Several PBL course participants mentioned that working in a team helped them to support each other when they missed information.

Peer support and teamwork: Students (particularly those from PBL courses) were also invited to share their teamwork experience and their online participation and interaction in general.

PBL students gave multiple variations of feedback regarding their online teamwork. Some students reported positive experiences because they were used to online teamwork even before the lockdown:

The online teamwork for my group was conducted mainly through WhatsApp group chat. We had great communication, and we were able to divide the work amongst us and set deadlines, regardless of our different busy schedules. It is functioning well in terms of making sure the messages reach us and tasks are accomplished without us having to meet physically, which is important because we find it hard to find common free time and we also live far from each other. Moreover, the current pandemic could not affect our teamwork negatively since the process was online from the beginning.

Another student mentioned lack of participation due to unfamiliarity with the team members before the lockdown started:

It may have been better if I had gotten to know my team members better; then the online communication may have been easier. Now, I have to spend more time thinking about how to express myself and how to get along with the team in order to make it positive, and it is not easy when I don't know some of them much yet.

Some other groups seemed to be too informal regarding teamwork online, so one student suggested:

It can be improved and made more effective by some more serious and formal meetings and discussions. It can be more effective by the cooperation of the leader; if the leader of the group would be cooperative and helpful, he/she could counsel the members of the group very well [...]

Institutional support: In general, participants reported positively on the general institutional support for providing timely IT support and facilities; they were also satisfied with the extent to which the instructors were ready for the shift and prepared to provide support. Nevertheless, they shared a desire for more opportunities to participate in synchronized online sessions because lectures tended to focus more on theoretical content and less on the practical aspects:

\section{One challenge is that the time allocated for the lectures was devoted to the instructor of the curriculum without students and was limited in the theoretical side without the practical, so a great educational gap developed in this side of learning that must be compensated later. Although most of the course consisted of calculations, it is hard to put these concepts into perspective and real-life application.}

Students also expressed their concerns about the exam format, mostly worrying about their final grades, e.g., "I wish the university would take measures to make sure that all exams are problem-solving, or mostly problem-solving and not just multiple-choice, since it could cause a lot of potential injustice for the students." Similar concerns were also shared about lab work, with several students suggesting the program provide options for virtual lab work. Finally, most participants suggested higher level and more organized facility support from the program/college, including ensuring all students had a strong internet connection for studying online.

\section{DISCUSSION}

We proposed a theoretical framework for understanding the factors influencing engineering students' readiness for change in an emergency online learning environment. A sequential explanatory mixedmethod research design was employed for data generation. In Phase 1 of the study, 140 participants completed an online survey, based on which an EFA displayed a four-factor structure, including initial preparedness and motivation for online learning, selfefficacy beliefs about online learning, self-directed learning online, and support. The EFA results suggested a logic that is close to the original design of the survey 
based on the theoretical framework, except that two factors loaded on one (the final factor regarding overall individual experience and the first factor regarding initial preparedness and motivation for online learning). This overlap of loading was reasonable and accepted because all the 10 items were related to initiation preparation and motivational aspects. Also, the Cronbach's reliability coefficients result (0.967) revealed adequate reliability for the survey as a whole and for each factor, accounting for $71.4 \%$ of the total variance. These results generally suggest that the established survey in this study is useful in examining engineering students' perception of the factors influencing their readiness for the emergency change to online learning in reaction to COVID-19.

The quantitative and qualitative results of the study demonstrate the advisability and suitability of the proposed theoretical framework. Engineering students reported mean scores for each of the four factors (ranging from 3.54 to 4.03 ) higher than the theoretical mean of 3 on a five-point Likert scale. The final version of factor 1 included 10 items related to motivation and initial preparation for change (Mean=3.90, $\mathrm{sdv}=1.07)$, reflecting individual attributes related to readiness for change. This also stresses the importance of change recipients' (students) perception of the discrepancy and appropriateness of the change and beliefs in personal gains from the anticipated change, perception, and beliefs which impact their dispositions, motivation, positive attitude, intentions, and behaviors in learning online (Armenakis, Harris, \& Field, 1999; Artino \& Stephen, 2009; Holt, Armenakis, Feild, \& Harris, 2007; Holt \& Vardaman, 2013). Equally important is students' confidence in their capability to manage online learning, which supports their adaptation to and success in an emergency (Hung, Chou, Chen, \& Own, 2010), as illustrated by factor 2, self-efficacy beliefs about online learning (Mean=4.03, sdv=1.00). Factor 3 was selfdirected learning online (Mean $=3.54, \mathrm{sdv}=0.96$ ), which is related to students' essential role in taking responsibility, managing their time, and participating in reflection and self-evaluation through online learning (Chou, 2012; Chu \& Tsai, 2009; Hung, Chou, Chen, \& Own, 2010). Factor $4(\mathrm{Mean}=3.97, \mathrm{sdv}=0.88)$ is the perception of support, which is a key factor supporting successful change implementation (Du \& Chaaban, 2020; Du, Chaaban, \& AlMabrd, 2019; Holt \& Vardaman, 2013). This study identified this factor as an important facilitator of online learning. Yet we observed a contrast between students' written and interview responses, which prioritize support regarding online platforms, facilities of materials, communication with instructors, and the qualitative data. Students indicate a need for more support pertaining to the type of learning activities in the course. Although students were satisfied with the initial support received, they also suggested more active, practice-oriented, interactive, and team-based activities in the prospective online learning environments. This student recommendation aligns with researchers' suggestions for an effective online learning environment (Kebritchi, Lipschuetz, \& Santiague, 2017; Miller, 2014; Radianti, Majchrzak, Fromm, \& Wohlgenannt, 2020).

In accounting for the factors influencing engineering students' readiness for online learning in the current study, the demographic factor of gender did not reveal statistically significant results. Significant differences were identified regarding pedagogical mode as a demographic factor, with PBL course students reporting higher readiness than non-PBL students in total and in two of the four factors. This result further evidence of PBL's impact on students' self-efficacy and motivation (Du, Ebead, Sabah, Ma, \& Naji, 2019; Du, Naji, Sabah, \& Ebead, 2020; Naji, Ebead, Al-Ali, \& Du, 2020). The results are also aligned with suggestions from previous studies that teaching methods that highlight active, interactive, and collaborative learning better support students' selfdirected learning online (Chu \& Tsai, 2009; Stewart, 2007; Yang \& Tsai, 2008). In comparing the four factors, the participants in this study reported significantly lower readiness in the factor of self-directed learning than in any of the other three factors, suggesting that more efforts should be made to support students' selfdirected online learning skills in future work.

The results of the study indicate the need for attention to the four factors influencing students' readiness for emergency change to online learning. In particular, we underlined some practical implications. First, effective communication from the program and instructors helped students understand the need and potential benefits of the change (Du \& Chaaban, 2020), which in turn encouraged them to build motivation, a positive attitude, and appreciation for online learning. Second, the pedagogical mode may impact students' motivation, attitude, and self-efficacy in online learning; for example, working in project teams may help reduce feelings of loneliness and solitude while isolated from peers. Third, as suggested by most participants, selfdirected learning online may be supported by teaching activities that involve more participation through interactive activities and teamwork (Hung, Chou, Chen, \& Own, 2010; Kebritchi, Lipschuetz, \& Santiague, 2017). Fourth, support plays a critical role in facilitating successful systemic change, meaning the program and instructors should monitor online teaching activities by observing the students' needs and providing timely scaffolding, particularly for those who struggle or feel isolated (Anderson, Imdieke, \& Standerford, 2011). For instance, Artino and Stephen (2009) provide useful guidelines for facilitating online discussions, including modeling appropriate discussion posts, reinforcing student contributions, requesting elaboration when necessary, and evaluating students' misunderstandings. In addition, it is helpful for programs and institutions to consider the integration of technologies in synchronized 
online learning environments that may help improve students' motivation, concentration, and engineering profession-related skills, such as problem-solving, communication, and collaboration online (Alkhatib, 2018, Radianti, Majchrzak, Fromm, \& Wohlgenannt, 2020; Wang, Wu, Wang, Chi, \& Wang, 2018). Active and interactive laboratory facilities providing hands-on experience (Potkonjak et al., 2016) and assessment methods that prioritize the above-mentioned skills maximize the values of online learning. Finally, while participants demonstrated the resilience to multiple challenges in the emergency online learning situation, they also suggested the need for emotional support through an academic support center, which can be a useful tool to help students cope more efficiently with challenges during the change process (Bouckenooghe et al., 2009; Herscovitch \& Meyer, 2002).

While the current study provides a good understanding of the important factors influencing engineering students' readiness for the emergency change to online learning, we were aware of its limitations. First, due to the short timeline to study the given topic of readiness for change, the study was conducted with a limited number of courses, and a limited number of participants completed the survey and took part in the interviews. Second, due to the gender segregation in the program enrollment, the participant samples are not balanced between male and female students. It was difficult to strictly control the sampling regarding gender and PBL v.s. Non-PBL courses in an emergency transition context. These conditions limit how the results can be interpreted. Further, this study did not compare results from different courses due to the abovementioned limitations. However, a comparative perspective could be useful in future studies exploring how instructors could design online courses to better support student motivation, selfefficacy, self-directed learning. Also, this study was conducted at the initial stage of the students' change to online learning; thus, the results are a snapshot of one particular transitional period. A longitudinal perspective in future studies may provide a better picture of the progression in online learning.

\section{CONCLUSION}

Future engineers are expected to be able to handle complexity and ongoing changes in the workplace. This study provides engineering students' views on factors that may support their readiness for the emergency change to synchronized online learning in the COVID-19 lockdown. The results of the study contribute to the field of engineering education through a theoretically sound framework that guided the empirical data collection and analysis, which in turn confirmed the suitability of the proposed framework. We hope that this is a useful first step to provide engineering educators and leaders with information on how to effectively intervene in a change process, facilitate a smooth transition, and make action plans that prepare future engineers.

\section{REFERENCES}

Ahmed, M. A. H. (2019). Tdeveloping A Two-Phase PostStratified Inverse Sampling to Reduce the Nonresponse Bias. Case Study: Students' Satisfaction Survey in Qatar University (Master's thesis). Retrieved from https:/ / quspace.qu.edu.qa/bitstream/handle/10 576/11664/Mahmood\%20Ahmed\%20_OGS\%20A pproved $\% 20$ Thesis.pdf? sequence $=1 \&$ isAllowed $=\mathrm{n}$

Alkhatib, O. J. (2018). An interactive and blended learning model for engineering education. Journal of Computers in Education, 5(1), 19-48. https:/ / doi.org/10.1007/s40692-018-0097-x

Al-Swidi, A., Huque, S. M. R., Hafeez, M. H., \& Shariff, M. N. M. (2014). The role of subjective norms in theory of planned behavior in the context of organic food consumption, British Food Journal, 116, 15611580. https:/ / doi.org/10.1108/BFJ-05-2013-0105

Anderson, D., Imdieke, S., \& Standerford, N. S. (2011). Feedback please: Studying self in the online classroom. International Journal of Instruction, 4, 315. Retrieved from https://eric.ed.gov/?id= ED522939

Armenakis, A. A., Harris, S. G., \& Feild, H. S. (1999). Making change permanent: A model for institutionalizing change interventions. In: W. A. Pasmore \& R. W. Woodman (Eds), Re- search in organizational change and development (Vol. 12, pp. 97-128). New York: JAI Press.

Armenakis, A. A., Harris, S. G., \& Mossholder, K. W. (1993). Creating readiness for organ- izational change. Human Relations, 46, 681-703. https:// doi.org/10.1016/j.iheduc.2009.02.001

Artino Jr, A. R., \& Stephens, J. M. (2009). Academic motivation and self-regulation: A comparative analysis of undergraduate and graduate students learning online. The Internet and Higher Education, 12(3-4), 146-151. https:/ / doi.org/10.1016/j.iheduc. 2009.02.001

Bandura, A. (1997). Self-efficacy: The exercise of control. New York: W.H. Freeman.

Bouckenooghe, D., Devos, G., \& Van den Broeck, H. (2009). Organizational change questionnaireclimate of change, processes, and readiness: Development of a new instrument. The Journal of psychology, 143(6), 559-599. https://doi.org/ $10.1080 / 00223980903218216$

Chen, J. B., Kolmos, A., \& Du, X. Y. (2020). PBL in Engineering Education - Forms of Implementation and Challenges: A Review of Literature. European Journal of Engineering Education. https:// doi.org/10.1080/03043797.2020.1718615 
Chou, P. N. (2012). The Relationship Between Engineering Students Self-Directed Learning Abilities and Online Learning Performances: A Pilot Study. Contemporary Issues in Education Research (CIER), 5(1), 33-38. https://doi.org/ 10.19030/cier.v5i1.6784

Chu, R. J., \& Tsai, C.-C. (2009). Self-directed learning readiness, Internet self-efficacy, and preferences for constructivist Internet- based learning environments among higher aged adults. Journal of Computer Assisted Learning, 25(5), 489-50. https:/ / doi.org/10.1111/j.1365-2729.2009.00324.x

Cohen, L., Manion, L., \& Morrison, K. (2013). Research methods in education. Routledge.

Creswell, J. W., \& Clark, V. L. P. (2017). Designing and conducting mixed methods research. Sage publications.

Du, X. Y., Chaaban, Y., Sabah, S., Al-Thani, A. M., \& Wang, L. (2020). Active Learning Engagement in Teacher Preparation Programs - a Comparative Study from Qatar, Lebanon and China. Asia Pacific Journal of Education, 1-16. https:/ / doi.org/10.1080/02188791.2020.1717436

Du, X. Y., Naji, K. K, Sabah, S., \& Ebead, U. (2020). Engineering students' group-based strategy use, forms of collaboration and perceptions of assessment in team projects - a case study in Qatar. International Journal of Engineering Education, 36(1(B)), 296-308.

Du, X., \& Chaaban, Y. (2020). Teachers' Readiness to change to Project based learning in Qatari government schools. Interdisciplinary Journal of Problem Based Learning, 14(1), 2020. https://doi.org/10.14434/ijpbl.v14i1.28591

Du, X., Chaaban, Y., \& AlMabrd, Y. M. (2019). Exploring the Concepts of Fidelity and Adaptation in the Implementation of Project Based Learning in the Elementary Classroom: Case Studies from Qatar. International Journal of Learning, Teaching and Educational Research, 18(9), 1-22. https://doi.org/ 10.26803/ijlter.18.9.1

Du, X., Ebead, U., Sabah, S., Ma, J., \& Naji, K. K. (2019). Engineering Students' Approaches to Learning and Views on Collaboration: How do both Evolve in a PBL Environment and What are their Contributing and Constraining Factors?. EURASIA Journal of Mathematics, Science and Technology Education, 15(11), em1774. https:/ / doi.org/10.29333/ejmste/ 106197

Forina, M., Armanino, C., Lanteri, S., \& Leardi, R. (1989). Methods of varimax rotation in factor analysis with applications in clinical and food chemistry. Journal of Chemometrics, 3(S1), 115-125. https://doi.org/10.1002/cem.1180030504
Guba, E. G. \& Lincoln, Y. S. (2005). Paradigmatic controversies, contradictions, and emerging confluences. In N. K. Denzin \& Y. S. Lincoln (Eds.), The Sage handbook of qualitative research (3rd ed.), Thousand Oaks, CA: Sage, 191-215.

Herscovitch, L., \& Meyer, J. P. (2002). Commitment to organizational change: Extension of a threecomponent model. Journal of applied psychology, 87(3), 474. https://doi.org/10.1037/00219010.87.3.474

Holt, D. T., Armenakis, A. A., Harris, S. G., \& Feild, H. S. (2007). Toward a comprehensive definition of readiness for change: A review of research and instrumentation. Research in organizational change and development, 16(2007), 289-336. Retrieved from https:/ / www.emerald.com/insight/content/doi/ 10.1016/S0897-3016(06)16009-7/full/html

Holt, D. T., \& Vardaman, J. M. (2013). Toward a comprehen- sive understanding of readiness for change: The case for an expanded conceptualization. Journal of Change Management, 13(1), 9-18. https://doi.org/10.1080/14697017.2 013.768426

Hsu, Y. C., Ho, H. N. J., Tsai, C. C., Hwang, G. J., Chu, H. C., Wang, C. Y., \& Chen, N. S. (2012). Research trends in technology-based learning from 2000 to 2009: A content analysis of publications in selected journals. Journal of Educational Technology $\mathcal{E}$ Society, 15(2), 354-370. Retrieved from https://www.jstor. org/stable/10.2307/jeductechsoci.15.2.354

Hung, M. L., Chou, C., Chen, C. H., \& Own, Z. Y. (2010). Learner readiness for online learning: Scale development and student perceptions. Computers $\mathcal{E}$ Education, 55(3), 1080-1090. https://doi.org/ 10.1016/j.compedu.2010.05.004

Henseler, J., Ringle, C. M., \& Sarstedt, M. (2015). A new criterion for assessing discriminant validity in variance-based structural equation modeling. Journal of the academy of marketing science, 43(1), 115135. https:/ / doi.org/10.1007/s11747-014-0403-8

Kebritchi, M., Lipschuetz, A., \& Santiague, L. (2017). Issues and challenges for teaching successful online courses in higher education: A literature review. Journal of Educational Technology Systems, 46(1), 4-29. https:/ / doi.org/10.1177/0047239516661713

Knowles, M.S. (1975). Self-directed learning: A guide for learners and teachers. New York: Association Press.

Kvale, S., \& Brinkmann, S. (2009). Interview. Hans Reitzel.

Jensen, L., \& Konradsen, F. (2018). A review of the use of virtual reality head-mounted displays in education and training. Education and Information Technologies, 23(4), 1515-1529. https://doi.org/10.1007/s10639017-9676-0

Martin, F., Ahlgrim-Delzell, L., \& Budhrani, K. (2017). Systematic review of two decades (1995 to 2014) of 
research on synchronous online learning. American Journal of Distance Education, 31(1), 3-19. https:/ / doi.org/10.1080/08923647.2017.1264807

Mayer, R. E. (2014). Incorporating motivation into multimedia learning. Learning and Instruction, 29, 171-173. https://doi.org/10.1016/j.learninstruc. 2013.04.003

Miller, M. D. (2014). Minds online: Teaching effectively with technology. Cambridge, MA: Harvard University Press.

Moore, M., \& Kearsley, G. (2005). Distance education: A systems view (2nd edition). Belmont, CA: Thomson Wadsworth.

Naji, K. K., Ebead, U., Al-Ali, A. K., \& Du, X. (2020). Comparing Models of Problem and Project-Based Learning (PBL) Courses and Student Engagement in Civil Engineering in Qatar. Eurasia Journal of Mathematics, Science and Technology Education, 16(8), em1867. https://doi.org/10.29333/ejmste/8291

Potkonjak, V., M. Gardner, V. Callaghan, P. Mattila, C. Guetl, V. M. Petrović, and K. Jovanović. 2016. Virtual laboratories for education in science, technology, and engineering: A review. Computers $\mathcal{E}$ Education, 95, 309-327. https:/ / doi.org/10.1016/ j.compedu.2016.02.002
Radianti, J., Majchrzak, T. A., Fromm, J., \& Wohlgenannt, I. (2020). A systematic review of immersive virtual reality applications for higher education: Design elements, lessons learned, and research agenda. Computers $\mathcal{E} \quad$ Education, 147, 103778. https:/ / doi.org/10.1016/j.compedu.2019.103778

Ryan, R. M., \& Deci, E. L. (2000). Intrinsic and extrinsic motivations: classic definitions and new directions. Contemporary Educational Psychology, 25(1), 54-67. https:/ / doi.org/10.1006/ceps.1999.1020

Stewart, R. A. (2007). Investigating the link between selfdirected learning readiness and project-based learning outcome: The case of international master's students in an engineering management course. Eur J of Engr Edu, 32(4), 453-465. https:/ / doi.org/10.1080/03043790701337197

Wang, P., Wu, P., Wang, J., Chi, H.-L., \& Wang, X. (2018). A critical review of the use of virtual reality in construction engineering education and training. International Journal of Environmental Research and Public Health, 15(6), 1204. https:/ / doi.org/10.3390/ ijerph15061204

Yang, F.-Y., \& Tsai, C.-C. (2008). Investigating university student preferences and beliefs about learning in the web-based context. Computers $\mathcal{E}$ Education, 50(4), 1284-1303. https://doi.org/10.1016/ j.compedu.2006.12.009 


\section{APPENDIX 1}

\section{Example questions for qualitative data}

\section{Written reflection}

- "Which online platform did you experience in this course?"

- "In which way do you think it has functioned well or not sufficiently well to support your learning? Please elaborate."

- "How do you perceive the options for participation in your online learning?"

- "In which ways have you participated online?"

- "Do you have any suggestions on how to provide sufficient opportunities for online participation?"

- "How do you conduct teamwork online? In what way do you think it is functioning well? And in what ways should/can it be improved? Please elaborate."

- "What major challenges have you experienced? Please elaborate the reasons."

- "What benefits may this experience of an emergency shift to online education bring to you in the long run?"

\section{Interview questions}

- "In what ways do you think online teaching and learning is an important and useful solution to the current situation?"

- "What do you think of the overall preparedness for this emergency? You, your peer students, instructors, and the institute (program, college and the university)?"

- "Can you please describe the online teaching you are experiencing?"

- "In what ways is it appropriate or not to support your learning (to reach the learning goals)?"

\section{http://www.ejmste.com}

